\title{
LATITUDINAL RELATIONSHIPS OF ESTERASE-6 AND PHOSPHOGLUCOMUTASE GENE FREQUENCIES IN DROSOPHILA MELANOGASTER
}

\author{
J. G. OAKESHOTT, G. K. CHAMBERS*, J. B. GIBSON and D. A. WILLCOCKS \\ Department of Population Biology, Research School of Biological Sciences, Australian \\ National University, P.O. Box 475, Canberra City A.C.T. 2601, Australia
}

Received 9.vii.81

\section{SUMMARY}

\begin{abstract}
Geographic variation in Esterase-6 (Est-6) and Phosphoglucomutase (Pgm) gene frequencies in Australasian populations of Drosophila melanogaster are compared with analogous data collated from 16 previous reports for North America and Europe/Asia. A large-scale latitudinal cline is found on all three zoogeographic zones for Est- 6 and overall, Est $-6^{1 \cdot 00}$ frequency increases from about 20 per cent around $20^{\circ}$ latitude to about 80 per cent approaching $50^{\circ}$ latitude. In contrast, there is no consistent evidence for a latitudinal cline in $\mathrm{Pgm}$ gene frequencies in any of the three zones, with $\mathrm{Pgm}^{1.00}$ frequency generally about 85 per cent and $\mathrm{Pgm}^{1 \cdot 20}$ and $\mathrm{Pgm}^{0.70}$ frequencies each between 5 per cent and 10 per cent. The consistent Est- 6 clines are attributed to latitudinal selection gradients but no consistent correlations are found between Est -6 gene frequencies and maximum or minimum temperature or rainfall which might be associated with these gradients. The directions of the Est-6 clines in fact run counter to expectations based on the in vitro thermostabilities of the respective allozymes.
\end{abstract}

\section{INTRODUCTION}

IN two previous papers we have described geographic variation in the frequencies of four common cosmopolitan chromosome inversions $(\operatorname{In}(2 L) t$, $\operatorname{In}(2 R) N S, \operatorname{In}(3 L) P$ and $\operatorname{In}(3 R) P)$ and alleles at two polymorphic enzyme loci (Alcohol dehydrogenase and Glycerol-3-phosphate dehydrogenase, i.e., $A d h$ and $G p d h$ ) in populations of $D$. melanogaster in three zoogeographic zones, Australasia, North America and Europe/Asia (Knibb et al., 1981; Oakeshott et al., 1981). For each of the six polymorphisms in each zone there was a statistically significant latitudinal cline covering between $25^{\circ}$ and $40^{\circ}$ latitude. Furthermore, for each polymorphism the direction of the latitudinal relationship was the same on the different continents. Since these continents have had very different histories of colonization and migration of D. melanogaster (Anderson, 1981) it was concluded that to some extent at least natural selection underlay the clines for all six polymorphisms.

This paper examines the latitudinal relationships of allelic frequencies for the Esterase-6 (Est-6) and Phosphoglucomutase $(P g m)$ polymorphisms in Australasia, North America and Europe/Asia. Preliminary evidence (Johnson and Schaffer, 1973) suggests the existence of a latitudinal cline for Est-6, but not for Pgm, in eastern U.S.A. (9 localities for Est-6

* Present address: Museum of Comparative Zoology, Harvard University, Cambridge, Mass. 02138, U.S.A. 
and 15 for Pgm over $18^{\circ}$ latitude). We test here whether the cline for Est -6 and the lack of it for Pgm recur in additional collections in North America and, more importantly, on other continents and in the Southern Hemisphere.

A second set of hypotheses examined here concerns possible climatic associations of Est- 6 and Pgm gene frequencies. In vitro thermostability differences exist between allozymes of both Est-6 and Pgm (Danford and Beardmore, 1979; Fucci et al., 1979) and we test whether these differences are reflected in associations between gene frequencies and temperature variables in wild populations.

\section{MATERIALS AND METHODS}

The Australasian collections were scored for Est-6 and Pgm after electrophoresis on cellulose-acetate sheets, using methods based on those of Trippa et al. (1978a). The Est -6 and Pgm gene frequencies from North America and Europe/Asia were collated from 16 previous reports; Band (1975), Charlesworth and Charlesworth (1973), Cochrane and Richmond (1979), Danieli and Costa (1977), Girard et al. (1977), Hollis (1972), Kojima et al. (1970), Langley et al. (1974, 1977), Pipkin et al. (1976), Triantaphyllidis et al. (1973), Trippa (1971), Trippa et al. (1974, 1978a, $1978 b)$ and Voelker et al. (1978).

Collections of less than 20 genes per locus were excluded from the analysis. The number of collections analysed and the mean and standard error of the number of genes sampled per collection were 66 and $106 \pm 7$ in Australasia, 43 and $295 \pm 31$ in North America and 27 and $925 \pm 209$ in Europe/Asia for Est-6, and 66 and $90 \pm 1$ in Australasia, 18 and $90 \pm 2$ in North America and 18 and $86 \pm 1$ in Europe/Asia for Pgm. The Australasian and North American data covered a wide range of latitudes and longitudes but with the exception of one Est-6 and two Pgm scores in Japan, the data for Europe/Asia were all obtained within about $10^{\circ}$ latitude and $20^{\circ}$ longitude in Europe.

The latitudes, longitudes and altitudes of collection sites were obtained from The Times Atlas of the World, Comprehensive Edition (The Times; London, 1967) and climatic data for adjacent weather stations from World Weather (Her Majesty's Stationery Office; London, 1967) and Climatic Averages Australia (Australian Government Publishing Service; Canberra, 1975). As in Wilks et al. (1980), Oakeshott et al. (1981) and Knibb et al. (1981), the four climatic variables used were maximum temperature (Tmaxaverage daily maximum in ${ }^{\circ} \mathrm{C}$ for the hottest calendar month), minimum temperature (Tmin-average daily minimum in ${ }^{\circ} \mathrm{C}$ for the coldest calendar month), maximum rainfall ( $\mathrm{Rmax}$ - total rainfall in $\mathrm{mm}$ for the wettest calendar month) and minimum rainfall ( $\mathrm{Rmin}$ - total rainfall in $\mathrm{mm}$ for the driest calendar month). Twenty year averages were used for all four climatic variables. For Est-6 only 125 of the total of 136 collections were close and at a comparable altitude, to a suitable weather station, while for $P g m$ the corresponding figures were 94 of 102 collections. For sites where a suitable weather station was found the average distance from collection site to weather station was $17 \pm 2$ miles.

Northern and southern latitudes were both analysed as positive values in order to represent distances from the equator. However, longitude was 
signed, with eastern values positive and western negative; longitude does not affect climate per se so it was just used as a general distance measure. Both rainfall variables were transformed into square roots while gene frequencies were angularly transformed and standardised for sample size.

\section{RESUlts}

In terms of the alleles present in the polymorphisms, the Australasian data confirm the previous results for Est-6 and Pgm in the Northern Hemisphere. The previous work indicated two common electrophoretically defined alleles, Est $-6^{1 \cdot 10}$ and $E s t-6^{1 \cdot 00}$ (map position $3-36 \cdot 8$ ); the combined frequencies of minor electrophoretic variants and occasional null alleles seldom exceed 5 per cent (e.g., Langley et al., 1974; Cochrane and Richmond, 1979). Both Est- $6^{1 \cdot 10}$ and Est $-6^{1 \cdot 00}$ occurred at polymorphic frequencies in all 66 Australasian samples and the only other electrophoretically defined allele we detected was Est $-6^{1 \cdot 25}$ (Franklin, 1981), which occurred sporadically at frequencies generally below 5 per cent.

Previously seven electrophoretically defined Pgm alleles (map position 3-43.4) have been reported from Northern Hemisphere populations, although only three, $\mathrm{Pgm}^{1.20}, \mathrm{Pgm}^{1.00}$ and $\mathrm{Pgm}^{0.70}$ are regularly polymorphic and one, $P g m^{1 \cdot 00}$, generally exceeds frequencies of 80 per cent (Trippa et al., 1970; Langley et al., 1974). Only $\mathrm{Pgm}^{1 \cdot 20}, \mathrm{Pgm}^{1 \cdot 00}$ and $\mathrm{Pgm}^{0.70}$ were consistently polymorphic in Australasia. The other electrophoretically defined alleles detected were $\mathrm{Pgm}^{1.50}$ and $\mathrm{Pgm}^{0.50}$ (Franklin, 1981) but their combined frequency nowhere exceeded 5 per cent.

Figures 1 and 2 summarise the North American, European and Australasian data in terms of the frequencies of $\mathrm{Est}^{1 \cdot 00}, \mathrm{Pgm}^{1 \cdot 20}$ and $\mathrm{Pgm}^{1 \cdot 00}$;

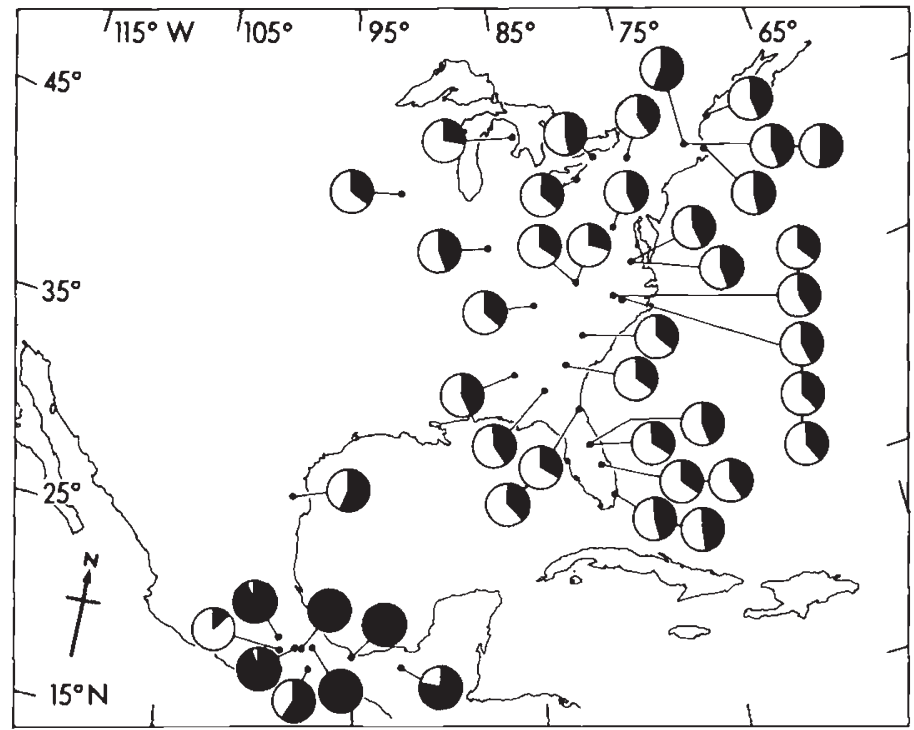

FIG. 1.-Est $-6^{1 \cdot 00}$ frequencies (white areas of Pie diagrams) in North America, Europe and Australasia. The frequency in a Japanese population not shown in the figure is 83 per cent at $42 \cdot 9^{\circ} \mathrm{N}, 141 \cdot 8^{\circ} \mathrm{E}$. 

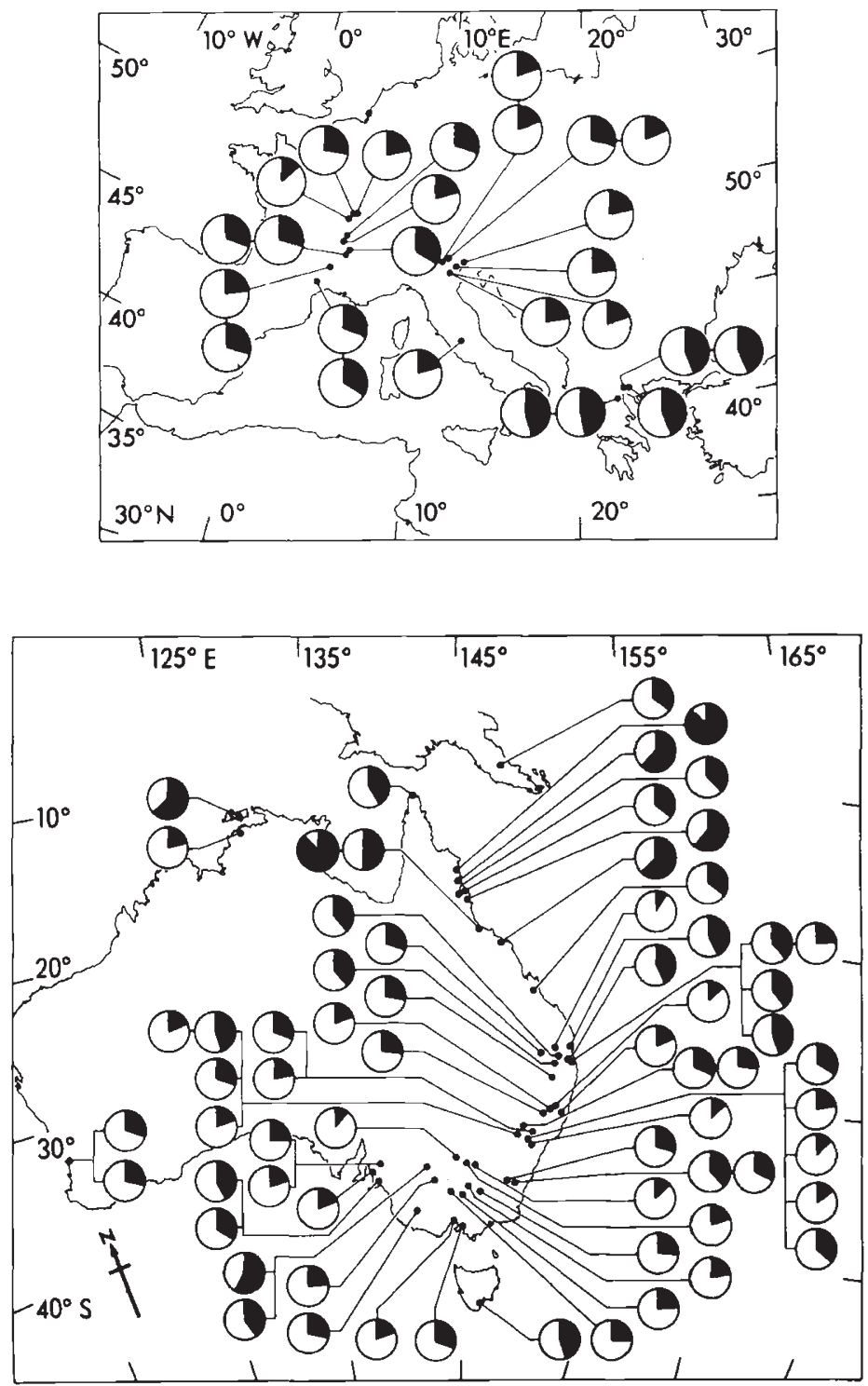

FIG. 1.-(cont.)

rare Est- 6 alleles are pooled with Est $-6^{1 \cdot 10}$ and rare Pgm alleles are pooled with $P g m^{0.70}$. Neither of the pooled frequency classes are analysed separately since they are not independent of the frequencies of Est ${ }^{1.00}$, or $\operatorname{Pgm}^{1 \cdot 20}$ and $\mathrm{Pgm}^{1 \cdot 00}$. (The full Australasian data are available from J.G.O. on request.)

The North American Est $-6^{1 \cdot 00}$ cline originally found by Johnson and Schaffer (1973) in eastern U.S.A. is substantiated by the additional data for that continent, particularly by the more southerly Mexican data of 
Pipkin et al. (1976); Est $-6^{1 \cdot 00}$ frequency increases from an average of about 20 per cent around $20^{\circ}$ latitude to about 60 per cent around $40^{\circ}$ latitude. Furthermore, this positive relationship between Est $-6^{1 \cdot 00}$ frequency and latitude extends through the higher latitudes represented by the European samples, in which Est $-6^{1.00}$ frequency increases still further, from about 60 per cent at $40^{\circ}$ latitude to about 80 per cent approaching $50^{\circ}$ latitude. Finally, the Australasian data indicate that a similar positive relationship also occurs in the southern hemisphere, where $E s t-6^{1 \cdot 00}$ frequency increases from about 40 per cent below $15^{\circ}$ latitude to about 70 per cent above $35^{\circ}$ latitude.

TABLE 1

Partial correlation ( $\mathrm{r}$ ) and standardised multiple regression (b) coefficients of Est $-6^{1 \cdot 00}, \mathrm{Pgm}^{1 \cdot 20}$ and $\mathrm{Pgm}^{1.00}$ frequencies on latitude, longitude and altitude. Only significant $\mathrm{b}$ values are presented, or considered in the proportions of variance explained by the regressions (Multiple $R^{2}$ )

\begin{tabular}{|c|c|c|c|c|c|c|c|}
\hline & & $r$ & & & $b$ & & \\
\hline & lat & long & alt & lat & long & alt & $\mathrm{R}^{2}$ \\
\hline Est $-6^{1.00}$ in & & & & & & & \\
\hline N. Amer & $0 \cdot 31^{*}$ & $0 \cdot 22$ & $0 \cdot 19$ & $0.48^{* *}$ & & & $0 \cdot 23$ \\
\hline Eur/Asia & $0.53^{* *}$ & $0 \cdot 21$ & $-0 \cdot 24$ & $0.48^{*}$ & & & 0.23 \\
\hline Aust & $0 \cdot 28^{*}$ & -0.09 & $0 \cdot 40^{* * *}$ & $0 \cdot 28^{*}$ & & $0.40^{* * *}$ & $0 \cdot 35$ \\
\hline $\mathrm{Pgm}^{1 \cdot 20}$ in ${ }^{-}$ & & & & & & & \\
\hline Eur/Asia & $-0 \cdot 20$ & -0.02 & $0 \cdot 11$ & & & & \\
\hline Aust & -0.07 & $0 \cdot 17$ & -0.01 & & & & \\
\hline $\mathrm{Pgm}^{1.00}$ in & & & & & & & \\
\hline N. Amer & $0 \cdot 27$ & -0.33 & -0.42 & & & & \\
\hline Eur/Asia & -0.35 & $-0 \cdot 85^{* * *}$ & $-0 \cdot 50$ & & $-0 \cdot 70^{* * *}$ & $-0 \cdot 38^{* *}$ & 0.79 \\
\hline Aust & -0.15 & 0.09 & $-0 \cdot 15$ & $-0 \cdot 25^{*}$ & & & 0.06 \\
\hline
\end{tabular}

* $P<0.05,{ }^{* *} P<0.01$, *** $P<0.001$.

† Insufficient data for $P g m^{1 \cdot 20}$ in North America (fig. 2).

Table 1 describes the clines statistically, in terms of the partial correlation and multiple regression coefficients of Est $-6^{1.00}$ frequency on latitude for each zoogeographic zone; all these coefficients are positive and statistically significant. There is not, however, any consistent relationship of Est $-6^{1 \cdot 00}$ frequency with longitude or altitude. Although there is a significant positive relationship with altitude in Australasia, this is not consistent in sign or statistically significant on the other two continents.

Table 2 describes statistically the overall Est $-6^{1 \cdot 00}$ frequency differences between continents, and the role of the latitudinal relationship of $E s t-6^{1.00}$ frequency in producing these differences. In fact about half the continental differences can be explained in terms of the latitudinal effects.

No consistent latitudinal relationships are obvious in fig. 2 for either $\mathrm{Pgm}^{1 \cdot 20}$ or $\mathrm{Pgm}^{1 \cdot 00}$, and the only association significant as both a partial correlation and multiple regression in table 1 is between $P g m^{1.00}$ frequency and longitude in Europe/Asia, where $P g m^{1.00}$ frequency declines eastward. (Even this longitudinal effect is largely just a reflection of a difference between Japan and Europe, for there was no collection in between to establish a regular cline.) Table 2 shows no overall continental or latitudinal 
TABLE 2

Analyses of variance for overall latitudinal and continental effects on Est- $6^{1 \cdot 00}, \mathrm{Pgm}^{1 \cdot 20}$ and $\mathrm{Pgm}^{1 \cdot 00}$ frequencies. The continental differences are assessed before and after removal of the latitudinal effects as covariates. Degrees of freedom are in parentheses

\begin{tabular}{|c|c|c|c|c|}
\hline & \multirow[b]{2}{*}{$\begin{array}{l}F \text { ratio for } \\
\text { latitude }\end{array}$} & \multicolumn{2}{|c|}{$\begin{array}{l}F \text { ratio for } \\
\text { continents }\end{array}$} & \multirow{2}{*}{$\begin{array}{c}\% \text { continental } \\
\text { differences } \\
\text { due to } \\
\text { latitude }\end{array}$} \\
\hline & & $\begin{array}{l}\text { before latitudinal } \\
\text { correction }\end{array}$ & $\begin{array}{l}\text { after latitudinal } \\
\text { correction }\end{array}$ & \\
\hline Est $-6^{1 \cdot 00}$ & $\begin{array}{l}50 \cdot 5^{* * *} \\
(1,132)\end{array}$ & $\begin{array}{l}27 \cdot 7^{* * *} \\
(2,132)\end{array}$ & $\begin{array}{l}16 \cdot 3^{* * *} \\
(2,132)\end{array}$ & $41 \%$ \\
\hline $\mathrm{Pgm}^{1 \cdot 20}$ & $\begin{array}{c}2 \cdot 1 \\
(1,87)\end{array}$ & $\begin{array}{l}44 \cdot 7^{* * * *} \\
(1,87)\end{array}$ & $\begin{array}{l}43 \cdot 8^{* * *} \\
(1,87)\end{array}$ & $2 \%$ \\
\hline $\mathrm{Pgm}^{1 \cdot 00}$ & $\begin{array}{c}1.6 \\
(1,99)\end{array}$ & $\begin{array}{c}1 \cdot 9 \\
(2,99)\end{array}$ & $\begin{array}{c}2 \cdot 2 \\
(2,99)\end{array}$ & $-18 \% \dagger$ \\
\hline
\end{tabular}

$\doteqdot$ i.e., the latitudinal effects, albeit non-significant, actually work against expression of the continental differences in $P g m^{1.00}$ frequency.

effects on $P g m^{1 \cdot 00}$ frequency, although there are continental, but not latitudinal, effects on $\mathrm{Pgm}^{1 \cdot 20}$ frequency (lower $\mathrm{Pgm}^{1 \cdot 20}$ frequencies occur in Europe/Asia, than in the other continents).

Table 3 examines the associations of Est-6 ${ }^{1.00}, P_{g m^{1 \cdot 20}}$ and $P g m^{1.00}$ frequencies with Tmax, Tmin, Rmax and Rmin. Most of the significant

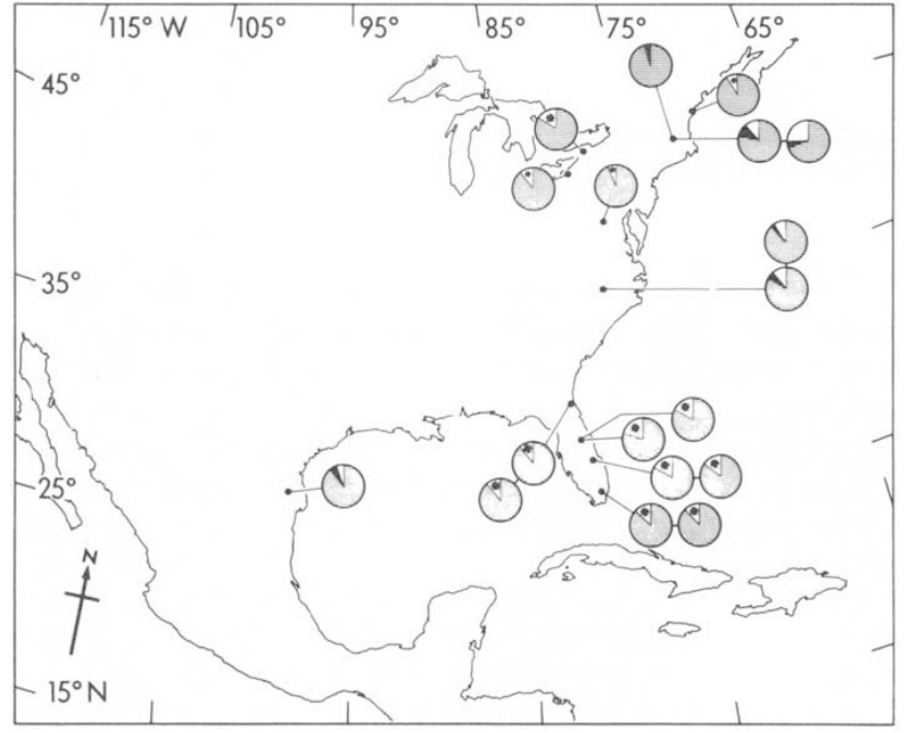

FIG. 2.- $P g m^{1.20}$ and $P g m^{1.00}$ frequencies (white and hatched areas respectively of the Pie diagrams) in North America, Europe and Australasia. Asterisked values indicate collections in which $P g m^{1.20}$ was not reported separately from $\mathrm{Pgm}^{0.70}$ and other rarer alleles. The frequencies in two Japanese populations not shown in the figure are 0 per cent $P g m^{1.20}, 67$ per cent $P g m^{1.00}$ and 0 per cent $P g m^{1.20}, 76$ per cent $P_{g m^{1.00}}$, both at $42 \cdot 9^{\circ} \mathrm{N}, 141 \cdot 8^{\circ} \mathrm{E}$. 

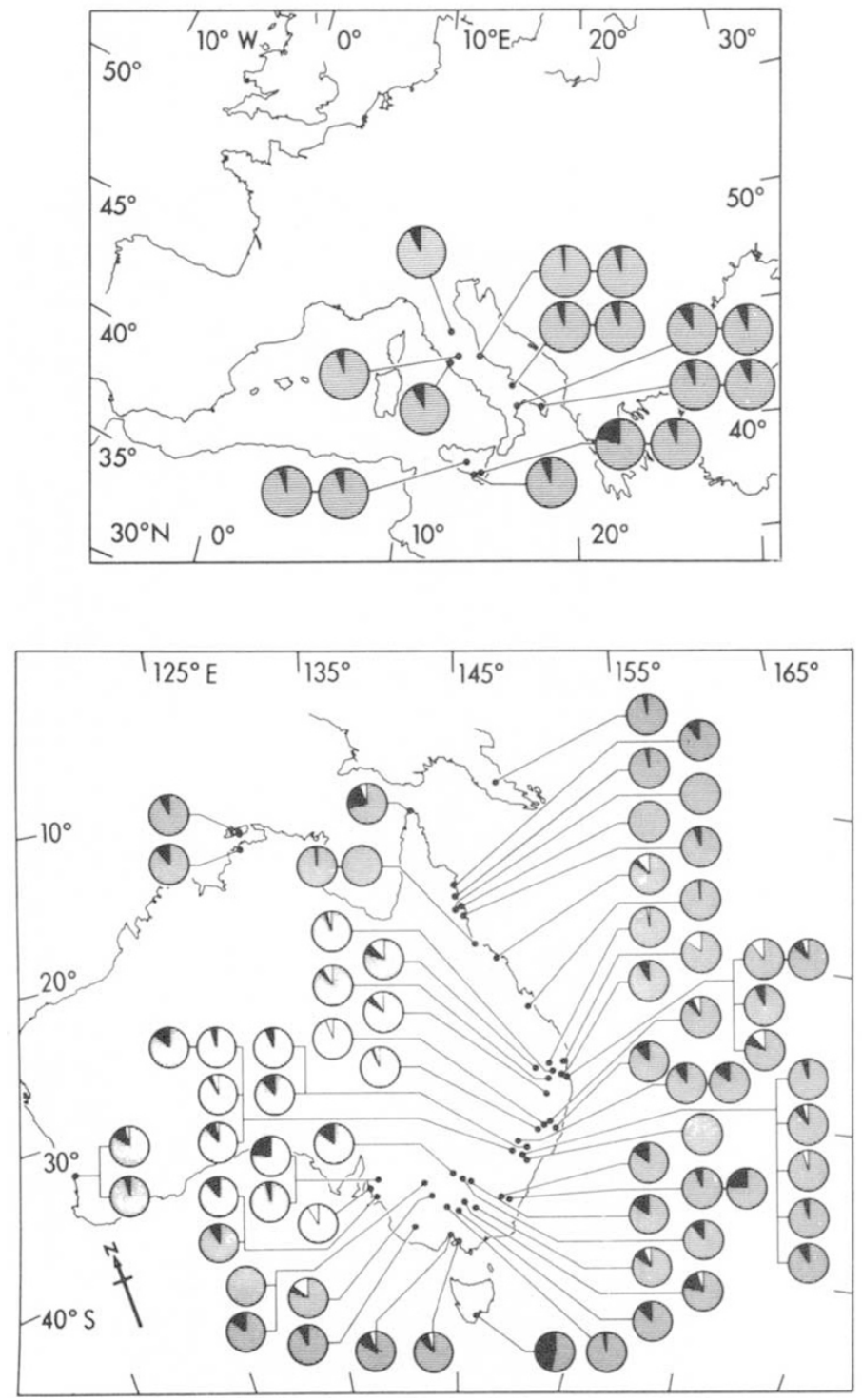

FIG, 2.-(cont.)

climatic associations which are found involve Est $-6^{1.00}$ and $P g m^{1.00}$ in Europe/Asia, but only one of these involves Tmax and none recurs on the other continents.

\section{Discussion}

Although only two of the 136 collections analysed were fixed for Est $-6^{1 \cdot 10}$ and none was fixed for Est $-6^{1 \cdot 00}$, a pronounced latitudinal cline in Est -6 gene frequencies has been found in North America, Europe/Asia and Australasia. Overall Est $-6^{1 \cdot 00}$ frequency increases from about 20 per 


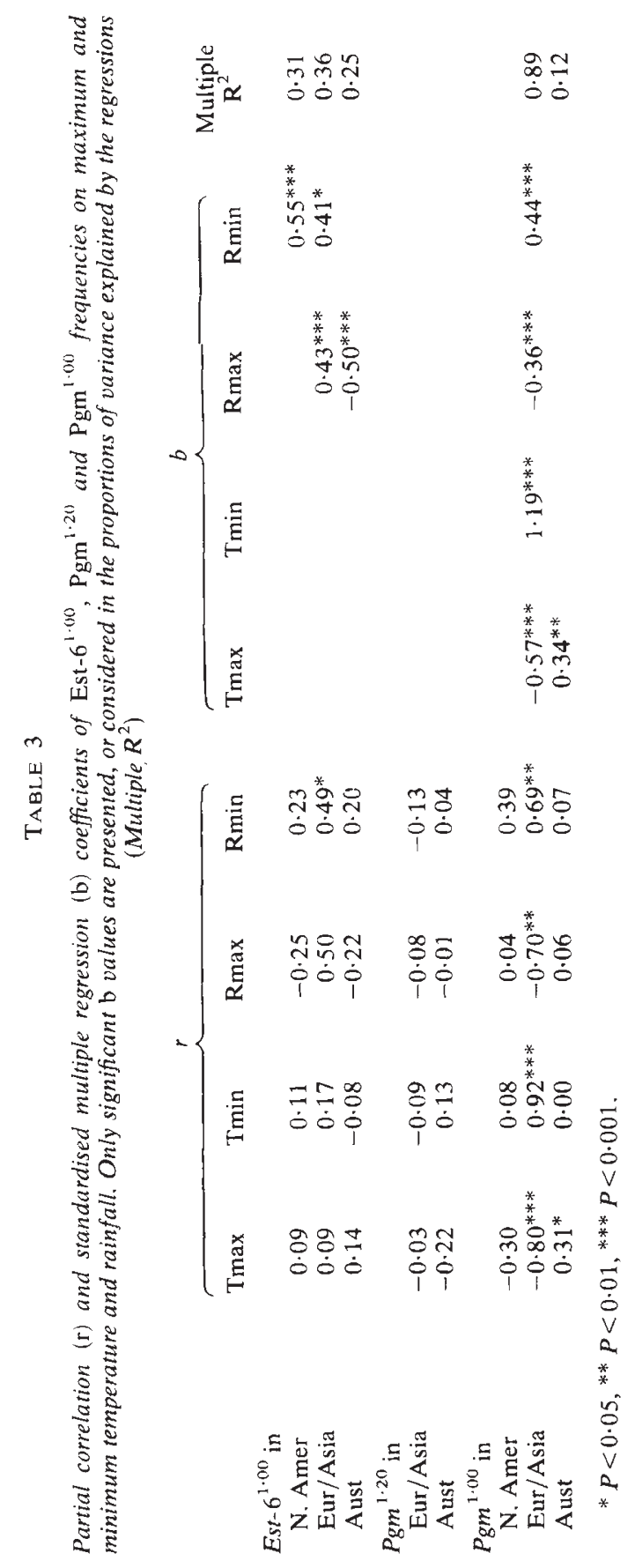


cent around $20^{\circ}$ latitude to about 80 per cent around $50^{\circ}$ latitude and it seems likely that this clinal pattern is produced at least in part by natural selection. Non-selectionist explanations seem incompatible with the consistency of the cline across immense geographic zones with very different histories of colonisation and migration of $D$. melanogaster.

For similar reasons it is doubtful that the Est-6 cline represents a transient state in the selective replacement of one Est -6 gene by another. It could be argued for example that Est $-6^{1 \cdot 10}$ had a recent equatorial origin but is advantageous at all latitudes and is slowly spreading away from the equator. While this argument cannot be disproved, it seems unlikely that the spread would have reached similar stages at all longitudes covered in the analyses.

It is therefore suggested that the Est-6 cline is maintained by stable latitude-dependent selection pressures, although the precise selection pressures involved cannot be deduced simply from the distributional data (Endler, 1973). It also must be admitted that the selection may not be acting directly on the locus; Est- 6 may simply mark a larger chromosome region which is selected. It is worth noting in this respect that Est-6 is consistently in linkage disequilibrium with $\operatorname{In}(3 L) P$, a common cosmopolitan inversion with breakpoints straddling the locus. Although In (3L)P decreases in frequency with increasing latitude on all three zoogeographic zones, the direction of the disequilibria $\left(E s t-6^{1 \cdot 00}, \operatorname{In}(3 L) P\right.$ gametes in excess) in fact works against the expression of the Est-6 cline (Voelker et al., 1978).

Of the selection mechanisms which might be acting directly on the Est-6 locus, some evidence for both temperature- and frequency-dependent selection has been obtained from laboratory studies. In the inbred population Danford and Beardmore (1979) studied, the thermostability of the enzymes produced by $E s t-6^{1 \cdot 00}$ was greater than that from Est $-6^{1 \cdot 10}$. This agrees with the evidence from laboratory perturbation experiments and fitness component analyses carried out between $25^{\circ}$ and $30^{\circ} \mathrm{C}$ which indicate higher equilibrium Est $-6^{1.00}$ frequencies than at temperatures between $18^{\circ}$ and $25^{\circ}$ (MacIntyre and Wright, 1966; Beardmore, 1970; Minawa and Birley, 1978; Oakeshott, 1979; Abedin et al., 1980). The selection at all the temperatures tested is frequency-dependent (Morgan, 1976; Birley and Beardmore, 1977 and references therein) and may involve mating behaviour (Aslund and Rasmuson, 1976) and the deposition of different products of ester metabolism in the media by different Est-6 genotypes (Birley and Beardmore, 1977).

Whether the temperature- or frequency-dependence is relevant to the selection in wild populations however remains doubtful. We have found no consistent Tmax-Est $-6^{1.00}$ frequency correlations underlying the latitudinal clines. And in fact the directions of the clines, with Est $-6^{1.00}$ at lower frequencies at the warmer, low latitudes, is opposite to that expected from the temperature effects in the laboratory studies. Furthermore, Franklin (1981), who monitored six populations over five years in the Hunter Valley, Australia, found Est $-6^{1.00}$ frequency consistently declined in the hot summer months and rose again in winter. This seasonality is consistent with the directions of the clines is opposite to the pattern expected from the laboratory work. 
Part of the explanation for this paradox may be the existence of electrophoretically cryptic thermostability variants within Est $-6^{1 \cdot 10}$ and Est$6^{1.00}$ in wild populations. A recent survey of four wild populations from eastern U.S.A. has revealed one common and two much rarer thermostability alleles within Est $-6^{1.00}$ and four relatively common thermostability alleles within Est $-6^{1 \cdot 10}$ (Cochrane and Richmond, 1979). One high priority for future research would seem to be a wider geographic and temporal survey of these variants.

Although Pgm was polymorphic in all but five of the 102 collections analysed here, there was little geographic variation in Pgm gene frequencies. Pgm ${ }^{1 \cdot 00}$ was the most common allele in every collection and its frequency was generally greater than 85 per cent. Nor was there any evidence, either within or across continents, for a cline in $\mathrm{Pgm}^{1.20}$ or $\mathrm{Pgm}^{1.00}$ frequencies. This marked contrast with the Est 6 variation is again paralleled by Franklin's (1981) seasonal data. Just as he found consistent seasonal variation in the frequencies of the Est-6 genes for which there are consistent latitudinal clines, he failed to find consistent seasonal variation in the frequencies of the $P g m$ genes for which there is no evidence for consistent latitudinal clines.

Geographic homogeneity of frequencies has been taken as firm evidence for selection by authors examining allozyme variation in Drosophila species with much more restricted geographic ranges than $D$. melanogaster (e.g., Ayala et al., 1974 and references therein). Therefore the large geographic scale encompassed by our analyses might suggest that selection was responsible for the observed consistency of Pgm gene frequencies. However, only relatively low levels of random migration are required for neutralist theory to account for geographic homogeneity of gene frequencies and, as in most geographic surveys of electrophoretic variation, the levels of migration between the populations analysed here have not been measured.

Despite this ambiguity, the postulated selection on Pgm concurs with evidence from laboratory perturbation experiments in which selection establishes equilibrium $\mathrm{Pgm}^{1.00}$ frequencies around 80 per cent. The fact that this equilibrium applies at $18^{\circ} \mathrm{C}, 25^{\circ} \mathrm{C}$ and $29^{\circ} \mathrm{C}$ (Oakeshott, 1979 ; Carfagna et al., 1980) is also consistent with the geographic homogeneity of $\mathrm{Pgm}$ gene frequencies and their lack of consistent association with Tmax, but it contrasts with biochemical evidence indicating differences between the in vitro thermostabilities of respective Pgm allozymes. The thermostabilities of the $P g m^{1.20}$ and $P g m^{1.00}$ products appear to be greater than those of $\mathrm{Pgm}^{0 \cdot 70}$, although there are also indications of electrophoretically cryptic thermostability variants within $P m^{1.00}$ (Trippa et al., $1978 b$; Fucci et al., 1979).

Thus the results of the latitudinal and climatic analyses for Pgm, like those for Est-6, and indeed for $A d h$ and Gpdh (Wilks et al., 1980; Oakeshott et al., 1981) seem unrelated to the in vitro thermostabilities of the relevant allozymes. The thermostability differences may be valuable biochemical tools but their adaptive value for flies in wild populations remains to be established.

Whatever the doubts about the mechanisms of selection involved however, overall an impressive picture emerges when the Est-6 and Pgm distributions are collated with the two previous papers in this series. The frequencies of alleles at four enzyme loci and four common cosmopolitan 
inversions have now been examined in North America, Europe/Asia and Australasia. Seven of the eight systems show consistent and complementary large-scale latitudinal clines on all three zoogeographic zones, and the other system, $P g m$, shows a consistent lack of relation to latitude on all three zones. Overall the results suggest that a substantial proportion of the electrophoretic and chromosomal variation in natural populations of D. melanogaster may be selectively maintained.

Acknowledgements.-We thank Dr M. A. Adena, Mr P. R. Anderson and Mr W. R. Knibb for valuable discussions and Mrs W. Eddey and Ms A. V. Wilks for excellent technical assistance. We are also grateful to Mr Keith Winters and Mr Ken Hall of the A.C.T. Regional Office of the Australian Bureau of Meteorology for advice and assistance in compiling the climatic data.

\section{REFERENCES}

ABEDIN, K., MCNAMARA, S., OSTERBUR, D., AND STEINER, W. W. M. 1980. Studies on the effect of temperature on fitness and fecundity at the Esterase- 6 locus in $D$. melanogaster. Drosophili Inform. Serv., 55, 10-11.

ANDERSON. P. R. 1981. Geographic clines and climatic associations of $A d h$ and $G p d h$ gene frequencies in Drosophila melanogaster. In Genetic Studies of Drosophila Populations, eds. J. B. Gibson and J. G. Oakeshott, pp. 237-250. Australian National University, Canberra.

ASLUND, S., AND RASMUSON, M. 1976. Mating behaviour as a fitness component in maintaining allozyme polymorphism in Drosophila melanogaster. Hereditas, 82, 175-178.

AYALA, F. J., TRACEY, M. L., BARR, L. G., MCDONALD, J. F., AND PEREZ-SALAS, S. 1974. Genetic variation in natural populations of five Drosophila species and the hypothesis of the selective neutrality of protein polymorphisms. Genetics, 77, 343-384.

BAND, H. T. 1975. A survey of isozyme polymorphism in a Drosophila melanogaster natural population. Genetics, 80, 761-771.

BEARDMORE, J. A. 1970. Ecological factors and the variability of gene pools in Drosophila. In Essays in Evolution and Genetics in Honour of Theodosius Dobzhansky, eds. M. K. Hecht and W. C. Steere, pp. 299-314. Appleton-Century-Crofts, New York.

BIRLEY, A. J., AND BEARDMORE, J. A. 1977. Genetical composition, temperature, density and selection in an enzyme polymorphism. Heredity, 39, 133-144.

CARFAGNA, M., FUCCI, L., GAUDIO, L., PONTECORVO, G., AND RUBINO, R. 1980. Adaptive value of Pgm polymorphism in laboratory populations of Drosophila melanogaster. Genet. Res., 36, 265-276.

CHARLESWORTH, B., AND CHARLESWORTH, D. 1973. A study of linkage disequilibrium in natural populations of Drosophila melanogaster. Genetics, 73, 351-359.

COCHRANE, B. J., AND RICHMOND, R. C. 1979. Studies of Esterase-6 in Drosophila melanogaster. II. The genetics and frequency distributions of naturally occurring variants studied by electrophoretic and heat stability criteria. Genetics, 93, 461-478.

DANFORD, N. D., AND BEARDMORE, J. A. 1979. Biochemical properties of Esterase-6 in Drosophila melanogaster. Biochem. Genet., 17, 1-22.

DANIEli, G. A., AND COSTA, R. 1977. Transient equilibrium at the Est-6 locus in wild populations of Drosophila melanogaster. Genetica, 47, 37-41.

ENDLER, J. A. 1973. Gene flow and population differentiation. Science, 179, 243-250.

FRANKLIN, I. R. 1981. An analysis of temporal variation at isozyme loci in Drosophila melanogaster. In Genetic Studies of Drosophila Populations, eds. J. B. Gibson and J. G. Oakeshott, pp. 217-236. Australian National University, Canberra.

FUCCI, L., GAUDIO, L., RAO, R., SPANO, A., AND CARFAGNA, M. 1979. Properties of two common electrophoretic variants of Phosphoglucomutase in Drosophila melanogaster. Biochem. Genet., 17, 825-836.

GIRARD, P., PALABOST, L., AND PETIT, C. 1977. Enzymatic variation at seven loci in nine natural populations of Drosophila melanogaster. Biochem. Genet., 15, 589-599.

HOLLIS, R. J. 1972. Allozymic variation in D. melanogaster from Virginia. Drosophila Inform. Serv., 49, 116. 
JOHNSON, F, M., AND SCHAFFER, H, E, 1973. Isozyme variability in species of the genus Drosophila. VII. Genotype-environment relationships in populations of $D$. melanogaster from the eastern United States. Biochem. Genet., 10, 149-163.

KNIBB, W. R., OAKESHOTT, J. G., AND GIBSON, J. B. 1981. Chromosome inversion polymorphisms in Drosophila melanogaster. I. Latitudinal clines and associations between inversions in Australasian populations. Genetics, in press.

KOJIMA, K., GILlesPIE, J., AND TOBARI, Y. N. 1970. A profile of Drosophila species' enzymes assayed by electrophoresis. I. Number of alleles, heterozygosities and linkage disequilibrium in glucose metabolising systems and some other enzymes. Biochem. Genet., 4, 627-637.

LANGLEY, C. H., ITO, K., AND VOELKER, R. A. 1977. Linkage disequilibrium in natural populations of Drosophila melanogaster: seasonal variation. Genetics, 86, 447-454.

LANGLEY, C. H., TOBARI, Y. N., AND KOJIMA, K. 1974. Linkage disequilibrium in natural populations of Drosophila melanogaster. Genetics, 78, 921-936.

MACINTYRE, R. J., AND WRIGHT, T, R. F. 1966. Responses of Esterase-6 alleles of Drosophila melanogaster and $D$. simulans to selection in experimental populations. Genetics, 53, 371-387.

MINAWA, A., AND BIRLEY, A. J. 1978. The genetical response to natural selection by varied environments. I. Short-term observations. Heredity, 40, 39-50.

MORGAN, P. 1976. Frequency-dependent selection at two enzyme loci in Drosophila melanogaster. Nature, 263, 765-766.

OAKESHOTT, J. G. 1979. Selection affecting enzyme polymorphisms in laboratory populations of Drosophila melanogaster. Oecologia, 43, 341-354.

OAKESHOTT, J. G., GIBSON, J. B., ANDERSON, P. R., KNIBB, W. R., ANDERSON, D. G., AND CHAMBERS, G. K. 1981. Alcohol dehydrogenase and glycerol-3-phosphate dehydrogenase clines in Drosophila melanogaster on different continents. Evolution, in press.

PIPKIN, S. B., FRANKLIN-SPRINGER, E., LAW, S., AND LUBEGA, S. 1976. New studies of the alcohol dehydrogenase cline in $D$. melanogaster from Mexico. J. Hered., 67, 258-266.

TRIANTAPHYLLIDIS, C. D., CHRISTODOU, C., AND BECKMAN, L. 1973. Polymorphism at two esterase loci in Drosophila melanogaster from northern Greece. Hereditas, 74, 25-30.

TRIPPA, G. 1971. New mutants of D. melanogaster: $\mathrm{Pgm}^{A}$ and $\mathrm{Pgm}^{\mathrm{B}}$. Drosophila Inform. Serv., 46, 42.

TRIPPA, G., CATANO, A., LOMBARDOZZI, A., AND CICCHETTI, R. 1978a. A simple approach for discovering common non-electrophoretic enzyme variability: a heat denaturation study in Drosophila melanogaster. Biochem. Genet., 16, 299-305.

TRIPPA, G., DANIELI, G. A., COSTA, R., AND SCOZZARI, R. 1978b. Phosphoglucomutase $(P g m)$ and Esterase-6 (Est-6) alleles in Drosophila melanogaster: an attempt to measure linkage disequilibrium. Genetica, 49, 225-227.

TRIPPA, G., LOVERRE, A., BARBERIO, C., ULIZZA, L., AND SCOZZARI, R. 1974. Studies on the Phosphoglucomutase (PGM) polymorphism in two successive years in natural populations of Drosophila melanogaster. Acad. Naz. Lincei Rend. Cl. Sci. Fis. Mat. Nat. Serv., VIII 56, 89-93.

TRIPPA, G., SANTOLAMAZZA, C., AND SCOZZARI, R. 1970. Phosphoglucomutase locus in Drosophila melanogaster: linkage and population data. Biochem. Genet., 4, 665-669.

VOELKER, R. A., COCKERHAM, C, C., JOHNSON, F. M., SCHAFFER, H. E., MUKAI, T., AND METTLER, L. E. 1978. Inversions fail to account for allozyme clines. Genetics, 88, 515-527.

WILKS, A. V., Gibson, J. B., OAKeshotT, J. G., AND CHAMBERS, G. K. 1980. An electrophoretically cryptic alcohol dehydrogenase variant in Drosophila melanogaster. II. Post-electrophoresis heat-treatment screening of natural populations. Aust. J. Biol. Sci., $33,575-585$. 